\title{
Augmented Reality in Tourism: An Innovative Way to Attract Tourists
}

\author{
Mrudula Gudadhe ${ }^{1}$, Divyaratna Bhanse ${ }^{2}$, Barbie Dhengre ${ }^{3}$, Trupti Patle $^{4}$, Kajal Mange ${ }^{5}$, \\ Vikram Patil ${ }^{6}$ \\ ${ }^{1}$ Professor, Department of Information Technology \\ Priyadarshini College Of Engineering, Nagpur, India, 4450016 \\ ${ }^{2,3,4,5,6}$ Students, Department of Information Technology \\ Priyadarshini College Of Engineering, Nagpur, India, 4450016
}

Received on: 02May,2021

Revised on: 02June ,2021

Published on: 04June,2021

\begin{abstract}
In the world of tourism, marketing is a key tool to introduce places to the public, get them to travel there, or encourage them to stay in a particular hotel. The forms of marketing have substantially changed during the past few decades due to technological advancements. E-Marketing, a recent product of this evolution, has revolutionized the world of marketing and had a positive impact on he hospitality and tourism industries in terms of customer satisfaction and revenue generation. This paper describes how augmented reality is redefining e-Marketing based on its unique features and capabilities in the context of the tourism and hospitality industry. In addition, several successful applications integrate augmented reality into the hotel and tourism industries.
\end{abstract}

Keywords- Augmented Reality, Marketing, Mobile Technology, Virtual Environment, Tourism.

\section{I- INTRODUCTION}

$\mathrm{T}$ ourism is one of the most rapidly growing economies. Tourism offers many opportunities for other businesses to thrive, such as hotels, transport, restaurants, etc. Yet, tourism faces many challenges today, including marketing and competitiveness. The concept of augmented reality (AR) is the use of computer-generated images to augment the experience of a real-world environment. Augmented reality permits marketers to have a combination of the physical world and also the digital world, that allows each users and brands to attach so much before or throughout and when a product is purchased[1]. Thus, augmented reality might give a much better understanding of what the client wishes to buy, use or enjoy. This might be in regards to accommodation, entertainment, or even special events.

A second way AR could revolutionize tourist experiences is by enabling tourists to view, preview, and access location-based data on holidays and destinations in an interactive and straightforward manner, from anywhere. They can preview and book their hotel, access information while they are in the hotel, navigate around their destination, translate written or spoken signs, as well as locate dining and entertainment options. Mobile applications make it simple to do all of this. This study provides a conceptual overview of AR and examines its potential for tourism promotion. It presents an overview of $\mathrm{AR}$ and looks at the possibilities for $\mathrm{AR}$ in tourism in the future.

\section{II- AUGMENTED REALITY}

Augmented Reality (AR) is one of these coming advances. It permits the consistent overlay of PC designs onto this present reality with a specific end goal to 


\section{International Journal of Innovations in Engineering and Science, www.ijies.net}

include additional data and upgrade the view of reality. It will be able to give more data in an easily accessible format. The potential outcomes for the use of this product in the visitor business are huge[2]. According to Azuma [3], AR is defined as a system with three basic features: a combination of virtual and real worlds, realtime interaction, and accurate $3 \mathrm{D}$ registration of the virtual and real world. AR technology is a real simulation by computer-generated visuals where a user can experience reality in a virtually created environment.

Augmented reality involves using virtual images created by computers and overlaying them on real-world objects in real-time. In other words, users can interact smoothly with virtual images. [4,3]. AR implementations in the public sphere have mostly been through smartphone apps since 2007 that use GPS navigation to pinpoint local points of interest and provide additional information [4].

Many industries use AR, including marketing, entertainment, sightseeing, tourism, fashion, and medicine. For instance, AR is used to present products to prospective customers and thus generate sales. A good example of this is IKEA, a furniture company that launched its augmented reality app to help people design their rooms with their products. Augmented reality is also used in a variety of other applications, including games, advertising, marketing, the arts, healthcare, architecture, construction, and entertainment. It is also used in the work place and for leisure and tourism[6].

\section{III- MARKETING WITH AUGMENTED REALITY}

Travelers can better appreciate a destination's authenticity with their smartphones by using them. The majority of tourists who have previously used smartphones will be more inclined to do so again; therefore, tourism marketing organizations should aim to improve the quality of travel information, offer more effective services, and develop applications for users to assist in improving destinations by providing travel information as well as boosting industry activities[7].

In augmented reality, digital content, such as web pages, graphics, or other images, is superimposed on the real world as they appear through a camera. As a result, the tourism industry may greatly benefit from AR. Tourists, for instance, will be able to see interactive $2 \mathrm{D}$ and $3 \mathrm{D}$ visual superimposition of augmented reality images. Images from this context include the cover or pages of magazines, billboards in a traffic circle, daily newspapers, or anything else found in daily life[8].
Using AR, brands can combine their digital strategy with consumer expectations. It can happen even during the advertising phase or when the products are on sale. AR allows users to augment any available objects or images in their surrounding as long as the objects or images have a unique visual profile, such as logos, hotel catalogue, and magazine covers and pages, posters, billboards, retail displays, business cards, signs and symbols, and so forth.[9]

Furthermore, AR seems like a less expensive alternative to conventional marketing methods. The costs of printbased marketing and advertising are higher and require continuous support. The use of digital platforms and web-based technology has the advantage of being less expensive. While AR-based marketing tends to have a higher development cost, in the long run, the operating costs remain fairly fixed[10].

\section{IV-TOURISM AR MARKETING CASE STUDY}

As technology becomes more mainstream, the tourism industry and the general public are beginning to see the potential of augmented reality for their travel needs. Early adopters are exploring new application areas rapidly as the technology matures. The purpose of this section is to examine the immediate impacts in the tourism industry of technology and the possibilities that may arise in the near future.

In the tourism and hospitality industry, consumers and investors are becoming increasingly intrigued by the advancements in AR technologies. As a result, these technologies are being designed and deployed for the end-user benefit[11].

\section{Museums}

A museum may create interactive learning scenarios that could transform visitors from passive observers into active actors and players. In that scenario, education is a more practical method. In fact, museum curators are capable of planning tailor-made excursions for youngsters of various age groups. Furthermore, such displays can be used not just for museums, but also for college classes[12].

Several museums around the world use QR codes (Quick response) in order to do audio tours of their collections, including Cleveland's Museum of Art and Bologna's Museum of Archaeology. It's a tour of the new galleries featuring ancient Near Eastern, Greek, Roman, Egyptian art, Byzantium, medieval art, and African art. When the user scans the code, they are taken to a web page with an audio tour. Art 


\section{International Journal of Innovations in Engineering and Science, www.ijies.net}

advertisements are placed in eleven different locations across Cleveland, including Tremont and Little Italy, as well as smaller posters are displayed throughout libraries and other public areas.[13]

As part of a campaign delivery along $\mathrm{QR}$ and $\mathrm{AR}$, the Virginia Museum of fine arts and the Martin Agency developed an app. A virtual museum has been created in thirty-three Richmond Starbucks and multiple cities along the East Coast. QR codes that launch the AR app (using Layer) can be used to turn any vacant lot or street into an art gallery, by plastering the art on a wall using one's smartphone[13].

\section{Accommodation Sector}

Incorporating AR elements into physical objects will allow hotels to connect their physical properties to their digital worlds. Hotel guests benefit from utilizing AR in their stay by maximizing their experience. In some cases, the hotel owner may offer a guest an app that offers directions to their hotel room after they sign in. A Blippar-Marriot Hotels advertisement appeared in the Wired magazine in an interactive format. An advertisement may show a video that showcases the innovative offerings of hotel chains to users of the application [14]. The Omni Hotels and Resorts company has created an application called Omni Live that users can use to view videos of chefs at work, virtual tours, and client reviews.

Premier Inn, the nation's largest lodging chain, offers the technology in one of its Hub hotels. Hotel rooms include wall maps depicting the surrounding area. The customer will study the information on the wall concerning local points of interest with their smartphone. Using the Hub as an example, hoteliers can probably use AR to enhance brochures and other printed materials. The ability to check reviews and suggestions of varied offerings while sitting at a hotel's bar or restaurant. As an alternative, guests could check their room's cleanliness, or see a map pop up of the hotel

\section{Restaurants}

Using the Snapchat app, Burger chain Bare Burger made their meatless Impossible Burgers virtually appear on guests' plates, partnering with AR menu app Kabaq to use this new AR technology. Bareburger users can now see an astoundingly realistic version of their lunch before they get up to the counter. According to Kabaq's study, desserts are first presented to guests with tablets. A true interactive marketing system was developed by Snapchat using programmable scanning.
There has been a 25 percent increase or tables dedicated to allowing people to eat virtually.

FoodPath is a multi-cuisine restaurant located in Mumbai. As part of their strategy to encourage people to return again and again, Smacar solutions integrated an augmented reality game through which customers can play the game by scanning printed materials like flyers, menu cards, and even the logo on their website.

The Inamo restaurant in London will give users options for choosing their table and customizing it with augmented reality. In addition, they can order food and view the live video feed from the kitchen through the multi-media system.

\section{Transportation Sector}

First Scotland AR applications make bus rides in Aberdeen more interesting for commuters. Through this application, users will be able to watch interactive videos on the digital displays in the rear of the seats. The app allows users to see bus information, theater trailers, and even purchase tickets. Departures Switzerland: A travel application based on augmented reality. An AR browser can assist users in finding out about all public transportation options within a certain area using visual information. Also, users will be provided with information about time periods.

Chhatrapati Shivaji International Airport (CSIA) is providing varied services assisted by AR technology. For better passenger experiences, the airport recently introduced a smartphone app that offers a range of advanced features. Using AR technology to provide information on nearby facilities to passengers has set this airport apart from other airports in India.

\section{V- CONCLUSION}

This research paper covered a description of AR technology, an analysis of tourism marketing, and several areas in which AR is applied to tourism. The aim of the study was to explore the potential benefits of AR as a marketing strategy. Research results discovered that current AR applications have the potential to provide relevant data and information about their surroundings, as well as advertising and promoting tourism businesses. Several examples from the Use Cases demonstrate that a multitude of institutions is implementing AR apps as a way to support pre-purchase decision-making. This indicates that these institutions view AR technology as particularly useful for supporting decisions about intangible products such as holidays and events. 


\section{International Journal of Innovations in Engineering and Science, www.ijies.net}

Tourism is facing certain obstacles to the adoption of this technology. Information and development are two major disadvantages. The field of AR remains in an experimental phase. It could also be a downside that users will be charged roaming charges when accessing the application. Additionally, travelers can run out of battery power. As a result, they rely on paper-based systems to understand transit locations, timings, and so on. There is a conflict between price and power. While it's true that AR is now available on mobile devices, true appreciation of its potential will require power. To get that power, we will have to pay a high price.

\section{REFERENCES}

[1] Ilhan, Ibrahim, and Evrim Celtek. "Mobile marketing: Usage of augmented reality in tourism." Gaziantep University Journal of Social Sciences 15, no. 2 (2016).

[2] Akram, Waseem, and Rakesh Kumar. "Study On Role And Applications Of Augmented Reality In Tourism: Its Challenges And Future Prospects." International Journal of Advanced Research in Computer Science 8.8 (2017).

[3] Azuma, Ronald T. "A survey of augmented reality." Presence: Teleoperators \& Virtual Environments 6.4 (1997): 355-385.

[4] Berryman, Donna R. "Augmented reality: a review." Medical reference services quarterly 31.2 (2012): 212 218.

[5] Yovcheva, Zornitza, Dimitrios Buhalis, and Christos Gatzidis. "Smartphone augmented reality applications for tourism." E-review of tourism research (ertr) 10.2 (2012): 63-66.

[6] Kounavis, Chris D., Anna E. Kasimati, and Efpraxia D. Zamani. "Enhancing the tourism experience through mobile augmented reality: Challenges and prospects." International Journal of Engineering Business
Management 4 (2012): 10.

[7] Kim, Hyun Hee, and Rob Law. "Smartphones in tourism and hospitality marketing: a literature review." Journal of Travel \& Tourism Marketing 32.6 (2015): 692-711.

[8] Höllerer, Tobias, and Steve Feiner. "Mobile augmented reality." Telegeoinformatics: Location-based computing and services 21 (2004).

[9] Carmigniani, Julie, Borko Furht, Marco Anisetti, Paolo Ceravolo, Ernesto Damiani, and Misa Ivkovic. "Augmented reality technologies, systems and applications." Multimedia tools and applications 51, no. 1 (2011): 341-377.

[10] Shabani, Neda, Arslan Munir, and Azizul Hassan. "EMarketing via augmented reality: A case study in the tourism and hospitality industry." IEEE Potentials 38, no. 1 (2018): 43-47.

[11] Nayyar, Anand, Bandana Mahapatra, D. Le, and G. Suseendran. "Virtual Reality (VR) \& Augmented Reality (AR) technologies for tourism and hospitality industry." International Journal of Engineering \& Technology 7, no. 2.21 (2018): 156-160.

[12] Wojciechowski, Rafal, Krzysztof Walczak, Martin White, and Wojciech Cellary. "Building virtual and augmented reality museum exhibitions." In Proceedings of the ninth international conference on $3 D$ Web technology, pp. 135-144. 2004.

[13] Meghan Kavanaugh (2018). The Future of Restaurant Menus? Augmented Reality. Retrieved from: http://upserve.com/restaurant-insider/the-futureofrestaurant-menus-augmented-reality/

[14] ÖZKUL, Emrah, and Sarp Tahsin KUMLU. "Augmented Reality Applications in Tourism." Uluslararası Güncel Turizm Araştırmaları Dergisi 3, no. 2 (2019): 107-122. 